RNL-SA- -19683

DE92 014703

RECENT IMPROVEMENTS IN SIZE EFFECTS

CORRELATIONS FOR DBTT AND UPPER SHELF

ENERGY OF FERRITIC STEELS
A. S. Kumar
B. S. Louden
F. A. Garner
M. L. Hamilton

January 1992

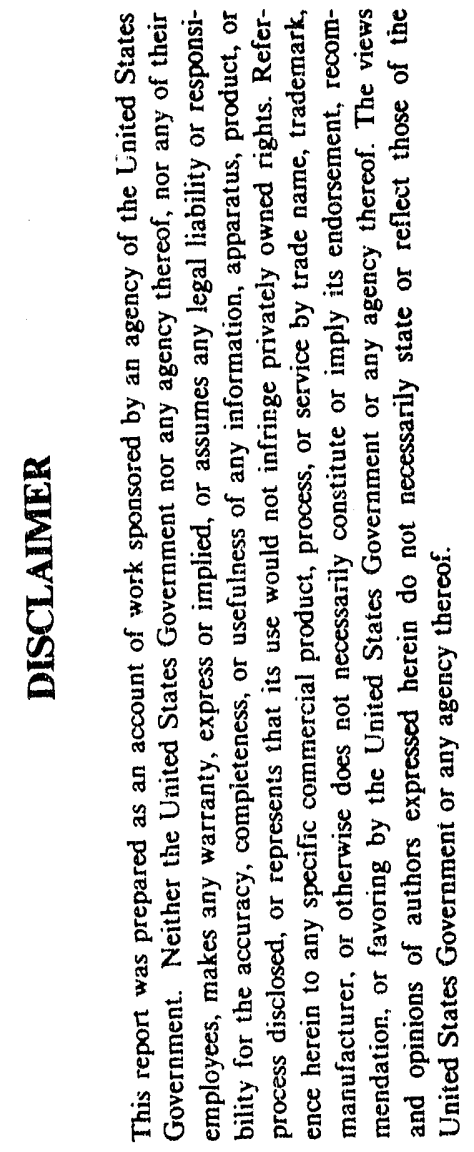

Presented at the

Symposium on Small Specimen Test Techniques

January 29-31, 1992

New Orleans, Louisiana

Work supported by

the U.S. Department of Energy

under Contract DE-AC06-76RLO 1830

Pacific Northwest Laboratory

Richland, Washington 99352

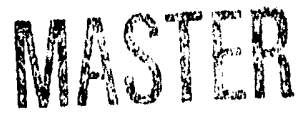




\title{
RECENT IMPROVEMENTS IN SIZE EFFECTS CORRELATIONS FOR DBTT AND UPPER SHELF ENERGY OF FERRITIC STEELS
}

\author{
A. S. Kumar ${ }^{1}$, B. S. Louden ${ }^{1}$, F. A. Garner², and M. L. Hamilton ${ }^{2}$ \\ 1 University of Missouri, Rolla, MO 65401 \\ 2Pacific Northwest Laboratory, Richland, WA 99352
}

Presented at the Symposium on Small Specimen Test

Techniques and Their Application to Nuclear Reactor Vessel

Thermal and Plant Life Extension

January 29-31

New Orleans, Louisiana 


\title{
RECENT IMPROVEMENTS IN SIZE EFFECTS CORRELATIONS FOR DBTT AND UPPER SHELF ENERGY OF FERRITIC STEELS
}

\author{
A. S. Kumar ${ }^{1}$, B. S. Louden ${ }^{1}$, F. A. Garner ${ }^{2}$, and M. L. Hamilton ${ }^{2}$ \\ 1 University of Missouri, Rolla, MO 65401 \\ ${ }^{2}$ Pacific Northwest Laboratory, Richland, WA 99352
}

\section{ABSTRACT}

Currently available correlations for the effects of specimen size on the USE were developed for relatively ductile steels and will not serve as well when the steels become embrittled. Size effects correlations were developed recently for the impact properties of less ductile HT9 to be applied to other initially more ductile steels as they lose their ductility during irradiation. These new correlations successfully predict the ductile brittle tra: sition temperature (DBTT) and the upper shelf energy (USE) of full size Charpy specimens based on subsize specimen data. The new DBTT and the USE correlations were tested against published experimental data on other ferritic steels and shown to perform successfully at lower USE particularly when both precracked and notched only specimens were employed.

\section{INTRODUCTION}

Neutron induced embrittlement of ferritic steels is of great importance for pressure vessels of existing fission reactors and for structural applications in breeder reactors and future fusion reactors. The development of a comprehensive data base on embrittlement, however, requires large irradiation volumes at uniform temperatures and neutron fluxes. The current irradiation facilities are extremely limited in irradiation space. In addition, there is invariably only a limited amount of archival material available for irradiation. 
It generally requires approximately ten full size charpy specimens to obtain the ductile brittle transition temperature (DBTT) and the upper shelf energy (USE) of steels. Acquiring data at several neutron fluences, compositions, and temperatures for a comprehensive data base is, therefore, not possible in a reasonable period of time. It is therefore necessary to rely on subsize specimens for determining the impact properties of irradlated materials. Enough third size specimens, for example, can be irradiated in the same volume as a full size specimen to provide complete data for two impact energy curves across the ductile brittle range of temperatures.

For fusion and breeder reactor applications both the temperatures and displacement levels required are larger than that of fission reactor pressure vessel steels. The use of high flux facilities such as the High Flux Isotope Reactor (HFIR) and the Fast Flux Test Facility (FFTF) is associated with other experimental difticulties. HFIR is a highly thermalized reactor with a large gamma heating rate (20-50 watts/gram). This can cause large temperature differences across full size $(1 \times 1 \times 5.5$ $\mathrm{cm}$ ) Charpy impact specimens, leading to difficulties in maintaining a uniform specimen temperature. Fast reactor facilities such as FFTF do not suffer as much from the large gamma heating problem, since the gamma heating rate is lower, (4-5 watts/gram). However, the minimum irradiation temperature for FFTF is $360^{\circ} \mathrm{C}$, above the values relevant for current fission reactor surveillance work and for some fusion reactor applications.

Another option is to irradiate specimens in relatively low power (1-10 MW) research reactors and develop size effects correlations that are valid for all similar steels at comparable service temperatures and levels of embrittlement.

The subsize Charpy specimens used in this study and others (1-9) are considerably smaller than the full size specimens. Decreasing the specimen dimensions lowers both the USE and the DBTT. Furthermore, the reduced dimensions of subsize specimens lead toward a plane stress condition, in contrast to 
the nominally plane strain conditions operating in full size specimens. A plane strain condition promotes brittle fallure whereas plane stress promotes ductile failure, thereby reducing the DBTT. In addition, the reduced fracture volume of subsize specimens reduces their USE. The reductions in USE and DBTT due to reduced specimen dimensions require that methodologies be developed for predicting USE and DBTT of full size specimens from subsize specimen data since it is the properties of full size impact specimens that are used in structural design. A number of attempts have been made in the past to develop the required methodologies, including the development of correlation factors that can be used to normalize USE and DBTT. The normalized values are equal to the ratios of the measured values and the respective normalization factors, and are expected to be invariant with specimen size.

Prior efforts to correlate subsize and full size USE involved the use of mainly ductile materials (USE $>200 \mathrm{~J}$ ) in the unirradiated state (3-10). A normalization factor equal to the fracture volume below the notch root has worked well to normalize the USE. The fracture volume was taken as $\mathrm{Bb}^{2}$ in the studies of Lucas et al. $(5,6)$ and as $(B b)^{3 / 2}$ in the studies of Corwin et al. $(3,4)$, where $B$ is the specimen width and $b$ is the ligament size. Neither of these normalization factors have been as successful, however, in correlating subsize and full size specimen data for ferritic materials, HTg and $\mathrm{A} 533 \mathrm{~B}$, in a relatively brittle condition (USE $\sim 100 \mathrm{~J}$ ) when they were tested $(10,11)$.

In an earlier stage of the current study, a normalization factor was developed for correlating the USE of full size and subsize specimens of brittle materials (10). The normalization factor worked well for HTg in the T-L orientation having a full size USE of $129 \mathrm{~J}$. The normalization factor also worked well for other materials in a relatively brittle state (USE $100 \mathrm{~J}$ ), such as the $9 \mathrm{Cr}-1 \mathrm{Mo}-\mathrm{VNb}$ in the quenched T-L and L-T conditions (4) and $12 \mathrm{Cr}-1 \mathrm{Mo}-\mathrm{VW}$ steel in the L-T orientation (3) used by other investigators. It has been found that the same normalization factor also works well for 
A533B pressure vessel steel (12) in a brittle state (USE $~ 60 \mathrm{~J}$ ). The success of this correlation relies on the fact that all of the specimen dimensions and the stress concentration factor at the notch root are important in the fracture of brittle materials, and these are all taken into account in the correlation.

None of the correlations developed so far, however, work well for both ductile and brittle materials Figure 1 shows how the earlier correlations of Conwin and the current authors compare. Note that Corwin's model works better at high USE and our earlier model worked better at low USE. Such a situation exists when a normally ductile steel, such as a reactor pressure vessel, embrittles significantly under neutron irradiation. A normalization factor was developed in this study to correlate the USE of full size and subsize specimens without regard to the ductile or brittle nature of the material. This correlation is the subject of this paper.

This approach is based on the partitioning of the USE into two contributions, that is, that required for crack initiation and that for crack propagation. To accomplish this partition both precracked and notched-only specimens were used. Whereas the USE of notched-only specimens is the sum of both crack initiation and propagation energies, the USE of precracked specimens reflects only crack propagation. The difference in USE values for the two types of specimens is thus a good estimate of the crack initiation energy. The utility of this partition will be expanded on in later sections of the paper.

In addition to the correlation for USE, a correlation methodology is also presented to predict the shift in DBTT for full size specimens based on subsize data. No other correlations in the published literature have been successful.

\section{EXPERIMENTAL PROCEDURE}

Dimensions for both full and subsize specimens are given in Figure 2. The full size specimen dimensions are in accordance with ASTM standard E23-86. While there are no standards available for subsize specimens, the dimensions used in this 
study for half and third size specimens are similar to those used in other investigations $(1-8)$. Note that the half size and third size specimens have the samie length.

All specimens used in this study were machined from HT9 plate material of heat 9607R2, which was manufactured by Electralloy Corporation for the US DOE fusion materials program. The chemical composition and tensile properties of this heat are given elsewhere (13). A series of heat treatments were performed on the plate stock to produce a tempered martensitic structure with a hardness of $255 \mathrm{DPH}$ and a prior austenite grain size of ASTM 5 to 6 . All specimens were taken from the base material in the transverse (T-L) orientation, in which the long axis of the specimen lies perpendicular to the rolling direction and the direction of elongation of the grains is the same as the direction in which the crack propagates. Specimens in this orientation will have the least resistance to fracture and will therefore provide a minimum estimate of fracture energy.

Adjustable anvils and interchangeable crossheads made possible the testing of different size specimens on the same instrumented drop tower. Data from each test were recorded on a digital oscilliscope and transferred to a desktop computer for storage and analysis.

Calibration of the instrumented hammer was performed by adjusting the load signal gain so that the maximum load obtained during dynamic testing was the same as the maximum load determined during the slow bend testing of a strain-rate insensitive alloy (6061 aluminum in the T51 heat-treatment) (1). In addition, a static calibration of the load cell was performed to insure that its response was linear over the desired range.

The impact velocity of the crosshead was calibrated by attaching a $1 \mathrm{~cm}$ long flag to the crosshead positioned so that the flag passed an infrared sensor just prior to impact, causing a change in voltage during interruption by the flag. 
The duration of this change was measured and the velocity was calculated as the average of at least ten calibration runs.

Temperature control for full size specimens was accomplished in a conditioning chamber where high temperatures were attained with a heated stream of air and low temperatures were reached by using cold nitrogen gas. Temperature control was achieved by adjusting the rate of gas flow into the conditioning chamber. Each specimen was kept at the test temperature for five to ten minutes prior to testing to ensure temperature stabilization to within $20^{\circ} \mathrm{C}$. Temperature control for the subsize specimens used the same sources of heated or cooled gas as the full size specimens but because the conditioning chamber was designed specifically for full size specimens, the miniature specimens were manually placed and aligned in the testing position and the gas was directed across the specimen surface. A thermocouple spot-welded across from the notch (opposite the surface being impacted) was used to monitor the temperature for each test.

Specimen placement for full size specimens was achieved by air-driven pistons that moved the specimen from its initial position, into and out of the conditioning chamber, and finally into the testing position using a rotary positioning arm. ASTM standard E23-86 provides for a maximum five second delay between obtaining the desired temperature and impacting the specimen. For full size specimens, the elapsed time between the exit of the sample from the conditioning chamber and the impact was approximately $0.2 \mathrm{~s}$. For subsize specimens, no specimen transfer was involved.

\section{RESULTS AND DISCUSSION}

The results of the impact testing on HT9 in the T-L orientation are shown in Figure 3 and Tables 1 and 2. The methodologies of correlating the DBTT and USE of full size and subsize data are presented below. 


\section{DBTT Correlation}

The DBTT shift due to irradiation-induced embrittlement is simulated by precracking the Charpy specimens, since the precracking increases the DBTT in a manner similar to irradiation. The DBTT shifts due to precracking are larger for subsize specimens than for full size specimens. The smaller the size the larger the shift in DBTT. Figure 3 shows the fracture energy of full, half, and third size specimens as a function of test temperature. Both notched-only and precracked specimen test results are presented.

The assumptions underlying the DBTT correlation are as follows. It is assumed that the fracture is controlled by the maximum tensile stress $\left(\sigma^{\prime}\right)$ ahead of the crack tip. The maximum tensile stress can be raised to the critical stress for crack propagation $\left(\sigma_{f}{ }^{*}\right)$ by the strain hardening in the plastically deformed zone at the crack tip. When the stress at the crack tip reaches the critical value $\left(\sigma_{f}{ }^{*}\right)$, also called the fracture stress, the crack propagates. It has been shown by Lucas et al. (5) that this fracture stress is a material property and is independent of specimen size.

It is proposed that a normalized value of DBTT can be defined as the ratio of the measured value of DBTT and $\sigma^{\prime}$. Furthermore, it is hypothesized that $\sigma^{\prime}$ controls the fracture process. Therefore, $\sigma^{\prime}$ is assumed to be the same for notched and precracked specimens.

In order to calculate $\sigma^{\prime}$ we must know the specimen dimensions, the stress concentration factor, $K_{t}$ at the notch root, and $P_{m}$, the maximum load developed in the Charpy impact test. $\sigma^{\prime}$ is given by

$$
\sigma^{\prime}=\left(K_{t}\right)\left(3 P_{m} L\right) /\left(B b^{2}\right)
$$

where $B$ is the specimen width and $b$ is the ligament size. The value of $P_{m}$ was not investigated in this study. In addition, the value of $P_{m}$ was not available for other published studies. An alternative approach was used to calculate it based 
on the fracture stress $\left(\sigma_{f}{ }^{*}\right)$ data of Lucas et al. (5) whose data are examined against the model presented in this paper. In another paper, Lucas et al. (6) showed that the fracture stress is related to $P_{m}$ by the equation

$$
\sigma_{f}^{*}=6.52 P_{m} / B b
$$

which leads to the equation

$$
P_{m}=\sigma_{f}^{*} B b / 6.52 \text {. }
$$

Equation (2) then reduces to

$$
\sigma^{\prime}=0.23 K_{t} L \sigma_{f}^{*} / b \text {. }
$$

The stress concentration factor, $K_{t}$ is given be the following equation (14).

$$
\begin{aligned}
& K_{1}=\frac{2(b / R+1)-f(b / R+1)^{1 / 2}}{4(b / R+1) / g-3 f} \\
& f=\frac{2(b / R+1)(b / R)^{1 / 2}}{(b / R+1) \arctan (b / R)^{1 / 2}+(b / R)^{1 / 2}} \\
& g=\frac{4(b / R)^{3 / 2}}{3\left[(b / R)^{1 / 2}+(b / R-1) \arctan (b / R)^{1 / 2}\right]}
\end{aligned}
$$

$R$ is the radius of the notch root, and $b$ is defined above. The calculated values of $K_{t}$ are $4.8,7.6$, and 6.3 for full-, half-, and third-size specimens, respectively. Note that $K_{t}$ for the third size specimen is smaller than that for the half-size specimen.

Figure 4 shows the normalized DBTT of the full size specimens plotted against the normalized DBTT of the subsize specimens. The data of Lucas et al. (6) for three steel compositions are shown in addition to the notched-only and precracked specimen data for HT9. The data of Lucas et al. was only available for full and third size specimens.

The topmost line joins data points marked $(\Delta)$ and $(\Delta)$ where $\Delta$ represents notched third size specimens and $\Delta$ represents the precracked third 
size specimens. The line has a slope of approximately unity. Similarly, the notched and precracked half size data are joined by a line of slope $\sim 1$.

The data of Lucas et al. on A710, in four different thermally aged conditions, are also connected by a line of slope unity. In addition, the data on the A508 in the two conditions also lie on a line with a slope approximately equal to unity.

The abovementioned variation of the normalized values of DBTT $\left(\mathrm{DBTT}_{n}\right)$ with precracking or thermal aging leads to the conclusion that

$$
\left.\left(\mathrm{DBTT}_{n}\right)_{\text {full size }}=(\mathrm{DBTT})_{n}\right)_{\text {subsize }}+\text { constant }
$$

Alexander and Klueh (16) reached a similar conclusion with one exception. In their case the DBTT was not normalized. The constant in equation (5) is dependent on both specimen size and material. For a given material and specimen size, however, the constant is independent of the alloy condition. In this context, the embrittlement introduced by precracking represents another alloy condition. Therefore, the shifts in $\mathrm{DBTT}_{n}$ due to thermal treatment or precracking are equal for full size and subsize specimens:

$$
\Delta\left(D B T T_{n}\right)_{\text {full size }}=\Delta\left(D B T_{n}\right)_{\text {subsize }} \text {. }
$$

Since the embrittlement introduced by precracking can be considered a simulation of the embrittlement introduced by a thermomechanical treatment or by irradiation, therefore, the shift in $\mathrm{DBTT}_{n}$ due to neutron irradiation will probably be the same for full size and subsize specimens. Tests are in progress to confirm this proposal (12).

Hu and Gelles (1) irradiated precracked half size specimens of HT9 base metal to $3 \times 10^{22} \mathrm{n} / \mathrm{cm}^{2}$ (E >0.1 MeV) or $\sim 15 \mathrm{dpa}$ in EBR-ll at temperatures ranging from 390 to $450^{\circ} \mathrm{C}$. The results are shown in Figure 5. The choice of precracked specimens in these experiments was based on the observations that the precracked data had less scatter than notched data in tests of 
unirradiated material. The shift in DBTT was $124^{\circ} \mathrm{C}$ for irradiation at $390^{\circ} \mathrm{C}$, but with increasing irradiation temperature, the $\triangle D B T T$ decreased. Based on the $\triangle D B T T$ correlation methodology described above, the $\triangle D B T T$ for precracked full size specimens at $390^{\circ} \mathrm{C}$ and $3 \times 10^{22} \mathrm{~h} / \mathrm{cm}^{2}$ would be $\sim 83^{\circ} \mathrm{C}$.

\section{USE Correlation}

For correlating the upper shelf energy (USE) of full and subsize specimens, testing of both notched and precracked specimens are required. The difference ( $\triangle$ USE) between the USE of notched and precracked specimens provides an estimate of the energy expended in plastic deformation and strain hardening to raise the maximum normal stress below the notch root to the fracture level. $\triangle U S E$ is thus an estimate of the crack initiation energy and should scale with the fracture volume equal to $\mathrm{Bb}^{2}$, where $\mathrm{B}$ is the specimen width and $b$ is the ligament size. The USE of Charpy specimens can thus be written as the sum of two terms as follows:

$$
U S E=\Delta U S E+U S E_{p}
$$

where $\triangle U S E$ is the crack initiation energy and USEp is the crack propagation energy. USEp is equal to the upper sholf energy of precracked specimens. The crack initiation energy can be written from the above equation as the difference between the upper shelf energy of notched-only and precracked specimens, and is given by:

$$
\triangle U S E=U S E-U S E_{p}
$$

A normalized value of $\triangle U S E$ is defined as the ratio of the measured $\triangle U S E$, and the fracture volume.

The measured values of USE and normalized values of $\triangle U S E$ ( $\triangle U S E_{n}$ ) are presented in Table 3 for the HT9 specimens used in this study. The last column in the table is the ratio of the $\triangle U S E_{n}$ and the average of the $\triangle U S E_{n}$ 
values of full, half, and third size specimens. The normalized values are within $\pm 7 \%$ of the average value, showing an excellent correlation.

A similar agreement between the normalized values of full and subsize specimens of A533B pressure vessel steel was observed in the work of Rosinski et al. (12). The normalized values were within $\pm 8 \%$ of the average values of $\triangle U S E_{n}$ showing once again an excellent correlation.

Alexander and Klueh (15) have also analyzed the effects of specimen size on the USE of a number of steels. The data were obtained from the work of Corwin and Ho: ughland (4), Abe et al. (9), Lucas et al.(6), Klueh et al. (15-19) and Corwin et al.(3). The analysis of Alexunder and Klueh (15) involves normalization of USE values by the fracture volume equal to $(B b)^{3 / 2}$. The normalization works well for steels having USE $>150 \mathrm{~J}$. However, when we examine their normalized data for those steels which have low values of USE, the normalized values of full, half, and third size specimens are substantiallv different. In addition, Alexander and Klueh (15) did not include two steel conditions from the work of Corwin and Houghland (4). These were $9 \mathrm{Cr}$-1MoVNb steels in the quenched T-L and L-T orientations. The USE for these steels was quoted to be $111 \mathrm{~J}$ and $72 \mathrm{~J}$, respectively. Table 4 compiles the USE for five steels with low USE selected from the tables of Alexander and Klueh (15). It also includes the $9 \mathrm{Cr}-1 \mathrm{MO}-\mathrm{VNb}$ steels in the quenched $\mathrm{T}-\mathrm{L}$ and $\mathrm{L}-\mathrm{T}$ orientations from Corwin and Houghland (4). The full size USE of these steels ranges from $64 \mathrm{~J}$ to $115 \mathrm{~J}$. The largest difference between the full size and subsize norinalized values is $76 \%$ when the full size USE is $72 \mathrm{~J}$ for the alloy 30176 , as shown in the last column of table 4. The variation of the normalized USE values of subsize specimens with those of the full size specimens is presented in Figures 6 and 7. Proximity of the data points to the diagonals in the figures represents a perfect correlation. It is important to note that all of the 
data points lie considerably above the diagonal, i.e. the subsize specimens exhibit a substantially higher ductility conpared to the full size specimens. It is evident that the volume normalization used by Alexander and Klueh (15), Corwin et al. (3), and Corwin and Hougland (4) is adequate for relatively ductile steels but not for normalizing the USE values of low ductility materials.

\section{CONCLUSION}

Pressure vessel materials at the beginning of life are sufficiently ductile (USE $200 \mathrm{~J}$ ). Volume normalization of USE of these materials will undoubtedly correlate the USE of full size and subsize specimens. However, at the end of life, the vessel materials are expected to be sufficiently embrittled so that their USE falls below $100 \mathrm{~J}$. USNRC Regulatory Guide1.99 suggests that the minimum USE be $68 \mathrm{~J}$. Therefore, an alternate normalization technique is required that will span the full range of ductility experienced by a steel during irradiation. The technique proposed in this paper is expected to be applicable to materials over a wider range of USE values.

This technique uses the difference between the USE for notched-only and precracked specimens and correlates it with fracture volume. Partitioning of the USE in this manner extends the validity of correlation to a wider range of USE values. In addition the use of normalized DBTT shifts due to environmental exposure were found to be independent of specimen size. Thus the DBTT and USE correlations developed in this study should be applicable to both ductile materials and those embrittled by irradiation. 


\section{REFERENCES}

[1] W. L. Hu and D. S. Gelles, in: Proc. Conf. on Ferritic Alloys for Use in Nuclear Energy Technologies, Snowbird, UT, June 1983, p. 631.

[2] R. W. Powell, G.D. Johnson, M. L. Hamilton, and F. A. Garner, in the Proc. of the ANS International Conf. on Reliable Fuels for Liquid Metal Reactors, Tuscon, AZ, September 1986, p. 4-17.

[3] Corwin, W. R., Klueh, R. L., and Vitek, J. M., Journal of Nuclear Materials, Vols. $122-123,1984$, p. 343.

[4] Corwin, W. R., and Hougland, A. M., The Use Small Scale Specimens for Testing Irradiated Material, ASTM STP 888, W. R. Conwin and G. E. Lucas, Eds., American Society of Testing and Materials, Philadelphia, 1986, p. 325.

[5] Lucas, G. E., Odette, G. R., Sheckherd, J. W., McConnell, P., and Perrin, J., The Use of Small-Scale Specimens for Testing Irradiated Material, ASTM STP 888, W. R: Corwin and G. E. Lucas, Eds., American Socieiy for testing and Materials for Testing and Materials, Philadelphia, 1986, p. 305.

[6] Lucas, G. E., Odette, G. R., Sheckherd, J. W., and Krishnadev, M. R., Fusion Technology, Vol. 10, 1986, p. 728.

[7] P. McConnell, J. W. Scheckerd, J. S. Perrin, and R. A. Wullaert, ASTM STP 888, Eds. W. R. Corwin and G. E. Lucas (American Society for Testing and Materials, 1986) p. 353.

[8] Ferguson, B. L., American Society for Metals. (ASM) Proceedings of American Institute of Mining, Metallurgical, and Petroleum Engineers, (AIME) Annual Meeting on "What Does the Chai, sy Test Really Tell Us?," Denver, CO, Feb. 1978, A.R. Rosenfield, et al., Eds., pp. 90-107.

[9] Abe, F., Noda, T., Araki, H., Okada, M., Narai, M., and Kayano, H., Journal of Nuclear Materials, Vol. 150, 1987, pp. 292-301.

[10] Louden, B. S., Kumar, A.S., Garner, F.A., Hamilton, M.L., and Hu, W. L., Journal of Nuclear Materials, Vols. 155 to 157, 1988, pp. 662-667.

[11] Kumar, A. S., Garner, F. A., and Hamilton, M. L., Effects of Radiation on Materials: 14th International Symposium (Volume II), ASTM STP 1046, N. H. Packan, R. E. Stoller, and A. S. Kumar, Eds., American Society for Testing and Materials, Philadelphia, 1990, pp. 487-495.

[12] S. T. Rosinski, A. S. Kumar, N. S. Cannon, M. L. Hamilton, "Application of Subsize Specimens in Nuclear Plant Life Extension," These proceedings. 
[13] T, A. Lechtenberg, ADIP Semiannual Progress Repart, DOE/ER-0045/8 (March 1983) p. 363.

[14] H. Neuber, Theory of Notch Stresses (Springer Publishers, Berlin, 1958) 2nd Ed., p. 71.

[15] D. J. Alexander and R. L. Klueh, "Specimen Size Effects in Charpy Impact Testing," ASTM STP 1072, John M. Holt, Ed., (American Society for Testing and Materials, 1990).

[16] R. L. Klueh, J. M. Vitek, and M. L. Grossbeck, Journal of Nuclear Materials, Vol. 103-104, 1981, pp. 887-92.

[i7] R. L. Klueh, J. M. Vitek, and M. L. Grossbeck, in Effects of Radiation on Materials: Eleventh Conference, ASTM STP 782, H. R. Brager ad J. S. Perrin Eds., American Society for Testing and Materials, 1982, pp. 648-64.

[18] R. L. Klueh, Metallurgical Transactions A, Vol. 20A, 1989, pp. 463-70

[19] R. L. Klueh and W. R. Corwin, Journal of Materials Engineering, Vol. 11, 1989, pp. 169-175. 
TABLE 1

HT-9 Charpy Data - DBTT

(Reference 10)

\begin{tabular}{llll} 
& DBTT $(K)$ & & $\Delta$ DBTT $^{\text {a }}$ \\
& Notched-only & Precracked & $(K)$ \\
\hline Full size & 271 & 275 & 4 \\
Half size & 226 & 246 & 20 \\
Third size & 209 & 239 & 30 \\
\hline
\end{tabular}

a DDBTT = precracked DBTT - notched DBTT

TABLE 2

HT-9 Charpy Data - USE

(Reference 10)

\begin{tabular}{llll} 
& USE $(\boldsymbol{N})$ & & Ratio $^{\text {a }}$ \\
\cline { 2 - 4 } & Notched-only & Precracked & \\
\hline Full size & 129 & 44 & 2.9 \\
Half size & 19 & 8 & 2.4 \\
Third size & 6 & 2 & 3 \\
\hline
\end{tabular}

a Ratio $=\frac{\text { Notched USE }}{\text { Precracked USE }}$ 


\section{TABLE 3 \\ HT-9 Charpy - USE \\ (Reference 11)}

\begin{tabular}{lcccc}
$\begin{array}{c}\text { Notched-only } \\
(\mathrm{J})\end{array}$ & $\begin{array}{c}\text { Precracked } \\
(\mathrm{J})\end{array}$ & $\begin{array}{c}\Delta \mathrm{USE} \\
\text { Fract. Vol. } \\
\left(\mathrm{J} / \mathrm{cm}^{3}\right)\end{array}$ & $\begin{array}{c}\Delta U \mathrm{USE}_{\mathrm{n}}{ }^{*} \\
\text { Average }\end{array}$ \\
\hline Full size & 129 & 44 & 133 & 1.01 \\
Half size & 19.1 & 8.0 & 123 & 0.93 \\
Third size & 5.9 & 2.3 & 140 & 1.06 \\
\hline
\end{tabular}

$* \Delta U_{S E}=\frac{\Delta U S E}{\text { Fracture Volume }}$

Average $=$ Average of $\Delta U S E_{n}$ of full, half, and third size specimens. 


\section{TABLE 4}

(References 4 and 15)

\begin{tabular}{|c|c|c|c|c|}
\hline \multirow[t]{2}{*}{ Alloy } & $\begin{array}{c}\text { Nominal } \\
\text { Compesition }\end{array}$ & $\begin{array}{c}\text { Specimen } \\
\text { Size }\end{array}$ & $\begin{array}{l}\text { Upper Shelf } \\
\text { Enerax J }\end{array}$ & $\begin{array}{l}\text { Normallized } \\
\text { USE }\left(\mathrm{J} / \mathrm{cm}^{3}\right)\end{array}$ \\
\hline & & & & \\
\hline \multirow[t]{2}{*}{3589} & $12 \mathrm{Cr}-1 \mathrm{MO}-\mathrm{V}-\mathrm{W}-2 \mathrm{NI}$ & Full & 106 & 148 \\
\hline & & Half & 17.8 & 182 \\
\hline \multirow[t]{2}{*}{3592} & $12 \mathrm{Cr}-1 \mathrm{Mo}-\mathrm{V}-\mathrm{W}-2 \mathrm{NI}$ & Full & 10.1 & 141 \\
\hline & (adjusted) & Half & 16.5 & 169 \\
\hline \multirow[t]{3}{*}{$9607-R 2$} & $12 \mathrm{Cr}-1 \mathrm{MO}-\mathrm{V}-\mathrm{W}$ & Full & 115 & 161 \\
\hline & & Half & 20.8 & 213 \\
\hline & & Third & 5.9 & 206 \\
\hline \multirow[t]{2}{*}{$\mathrm{A} 302 \mathrm{~B}$} & $1.5 \mathrm{Mn}-0.2 \mathrm{C}$ & Full & 64 & 89 \\
\hline & & Third & 3.8 & 131 \\
\hline A508B & $0.6 \mathrm{Mn}-0.6 \mathrm{Ni}-0.6 \mathrm{Mo}-0.2 \mathrm{C}$ & Full & 74 & 103 \\
\hline \multicolumn{2}{|c|}{ (reaustenitized) } & Third & 4.1 & 143 \\
\hline \multirow[t]{3}{*}{30176} & $9 \mathrm{Cr}-1 \mathrm{MO}-\mathrm{V}-\mathrm{Nb}$ & Full & 111 & 153 \\
\hline & (quenched, L-T) & Half & 18.9 & 194 \\
\hline & & Third & 5.7 & 199 \\
\hline \multirow[t]{3}{*}{30176} & $9 \mathrm{Cr}-1 \mathrm{Mo}-\mathrm{V}-\mathrm{Nb}$ & Full & 72.0 & 100 \\
\hline & (quenched, $T-L$ ) & Half & 15.3 & 156 \\
\hline & & Third & 5.1 & 176 \\
\hline
\end{tabular}




\section{COMPARISON OF UPPER SHELF NORMALIZATION METHODS}

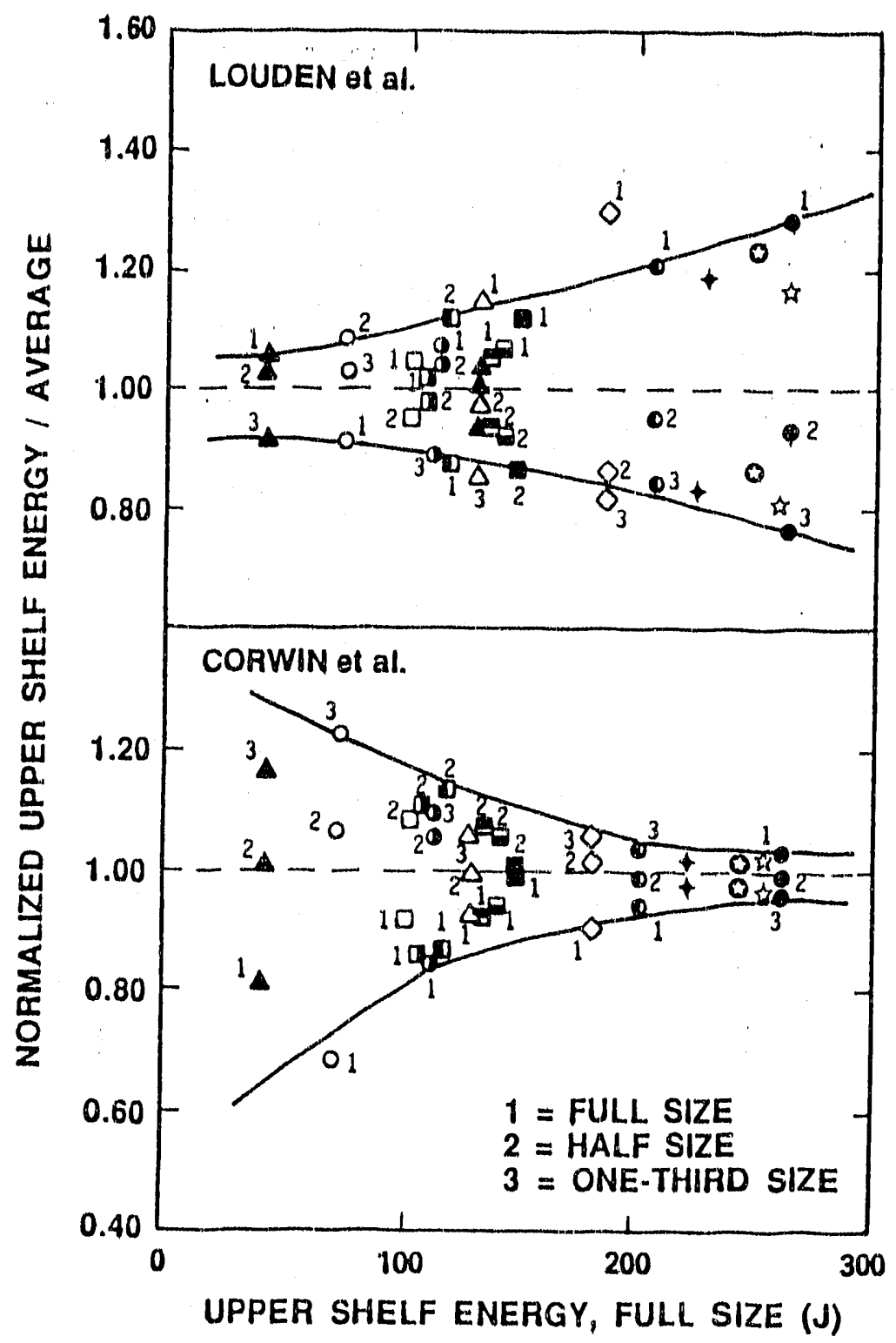

$\triangle$ HTS, PRECAACKED. TL $\triangle \mathrm{HTS}, \mathrm{TL}$

9 Cr. $1 \mathrm{MO} \cdot \mathrm{VNG}$

$O$ QUENCHED. TL

- NORM. AND TEMPEAED, TL.

- QUENCHED. LT

- NOAM, AND TEMPERED, LT $12 \mathrm{Cr} \cdot 1 \mathrm{MO} \cdot \mathrm{VW}$

D XAA.3592. LT

-1 9607.R2. LT

(1) XAA-3589, LT

XAA.3588, LT

- XAA-3587, LT

91354, LT

ठ HSLA, LT

is $9 \mathrm{Cr} .1 \mathrm{~W}, \mathrm{TL}$

- $9 \mathrm{Cr} \cdot 2 \mathrm{~W}, \mathrm{TL}$

$+9 \mathrm{Cr} .4 \mathrm{~W}, \mathrm{TL}$

Figure 1 

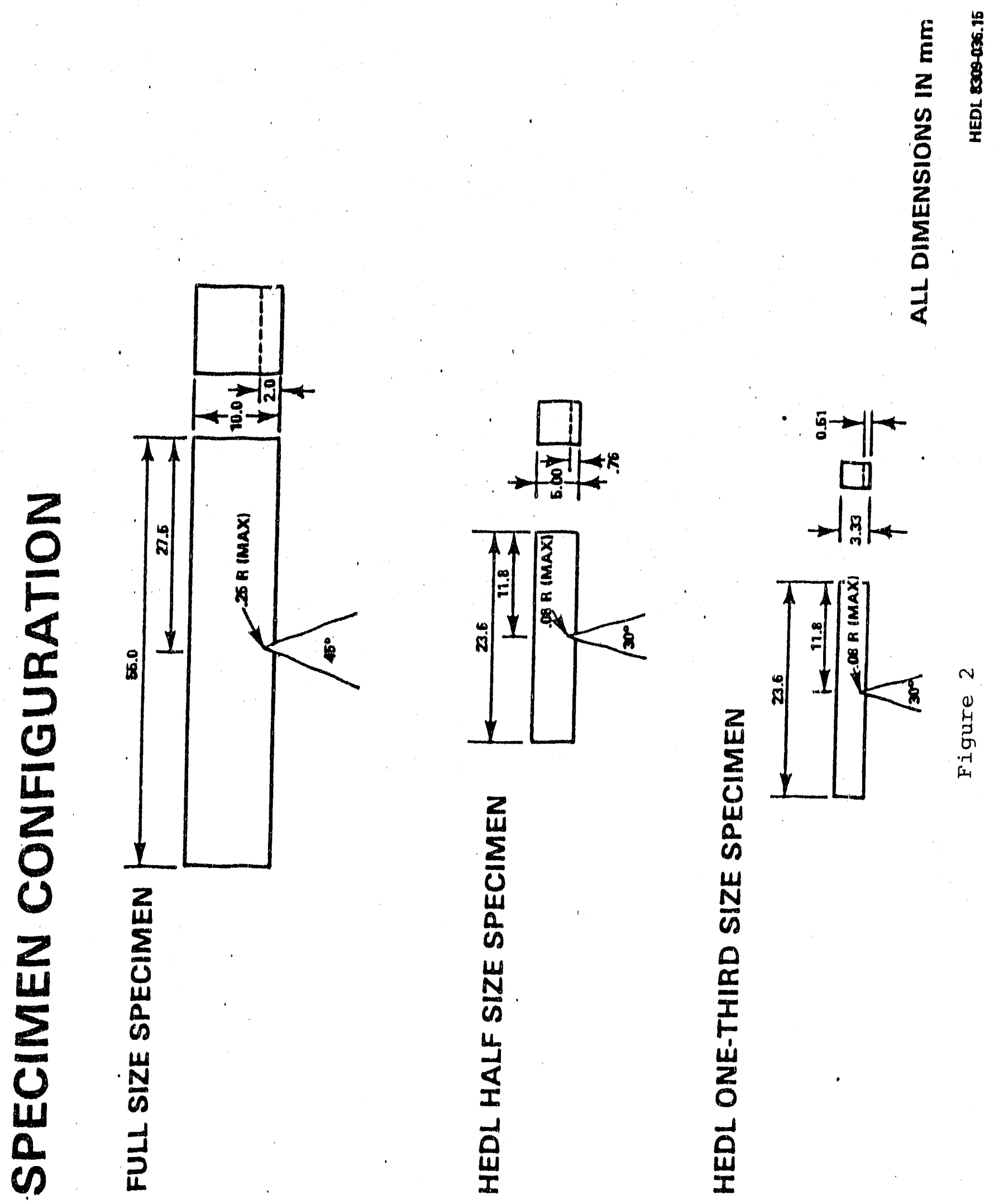

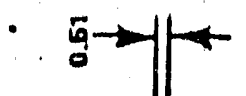

[]
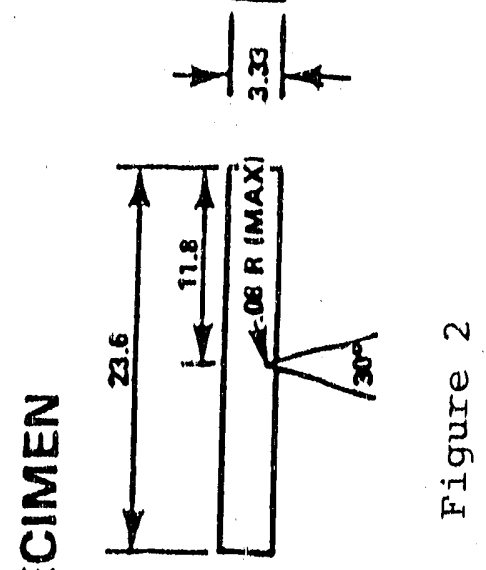
TEST RESULTS

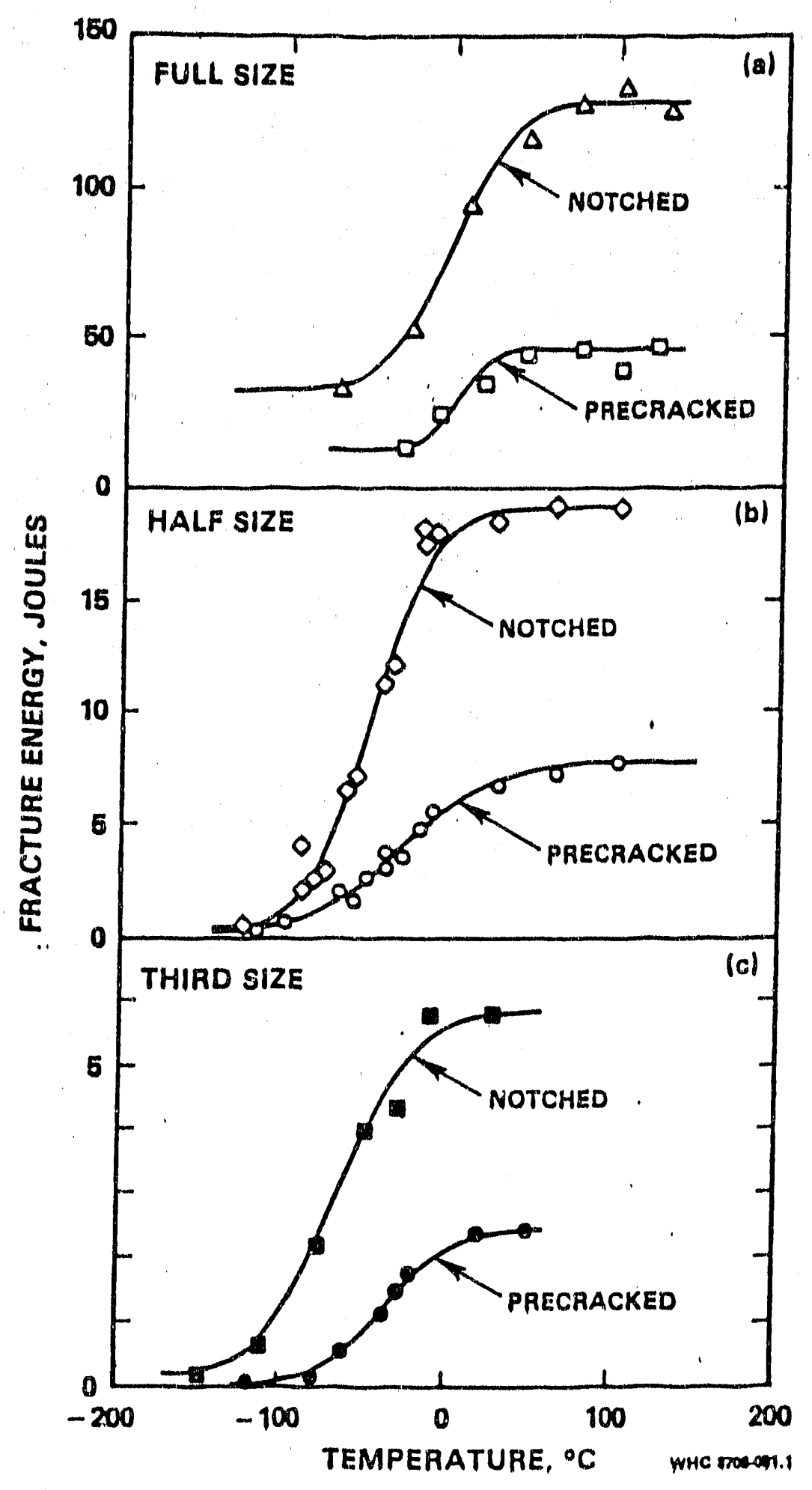

Figure 3 


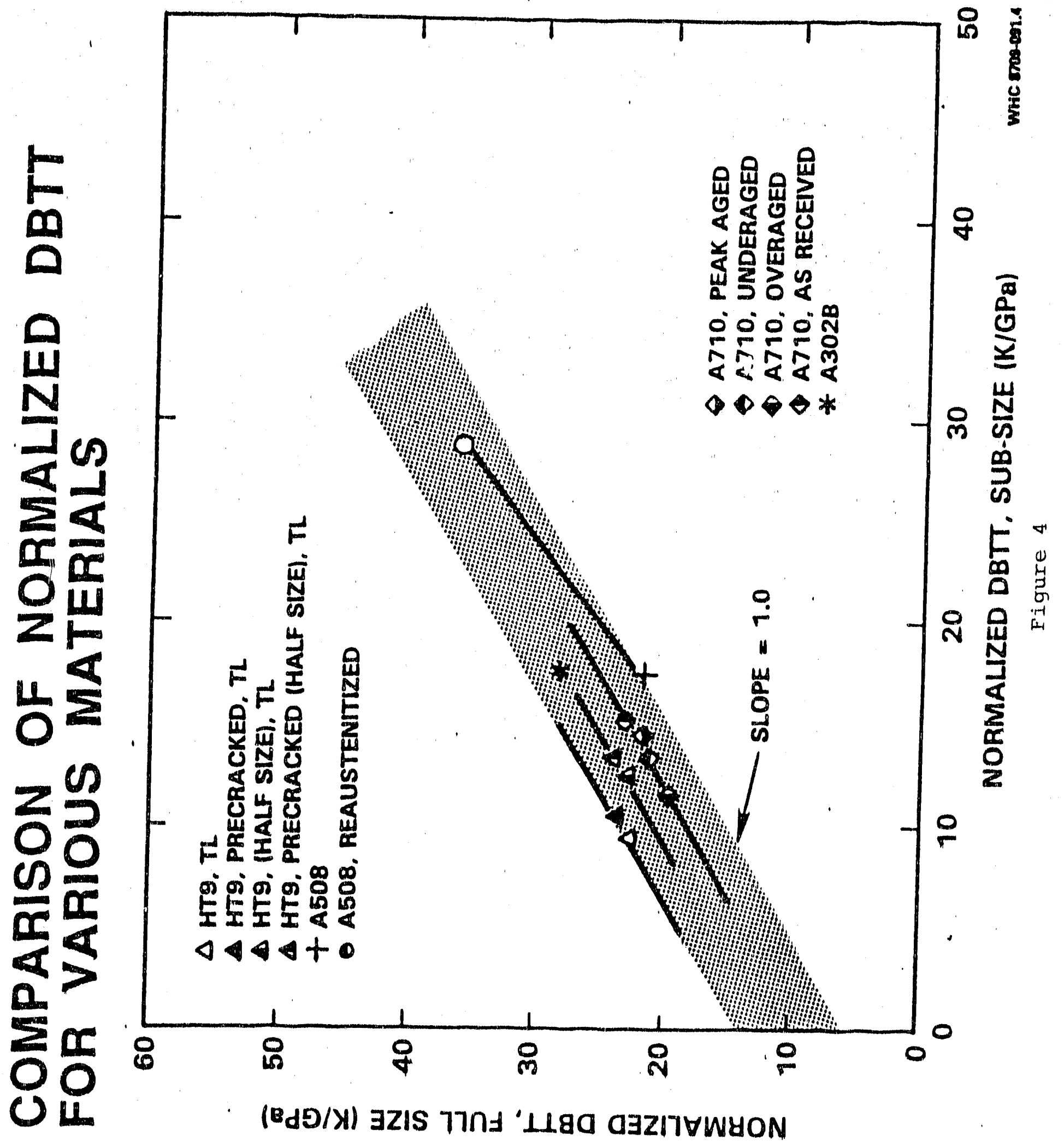



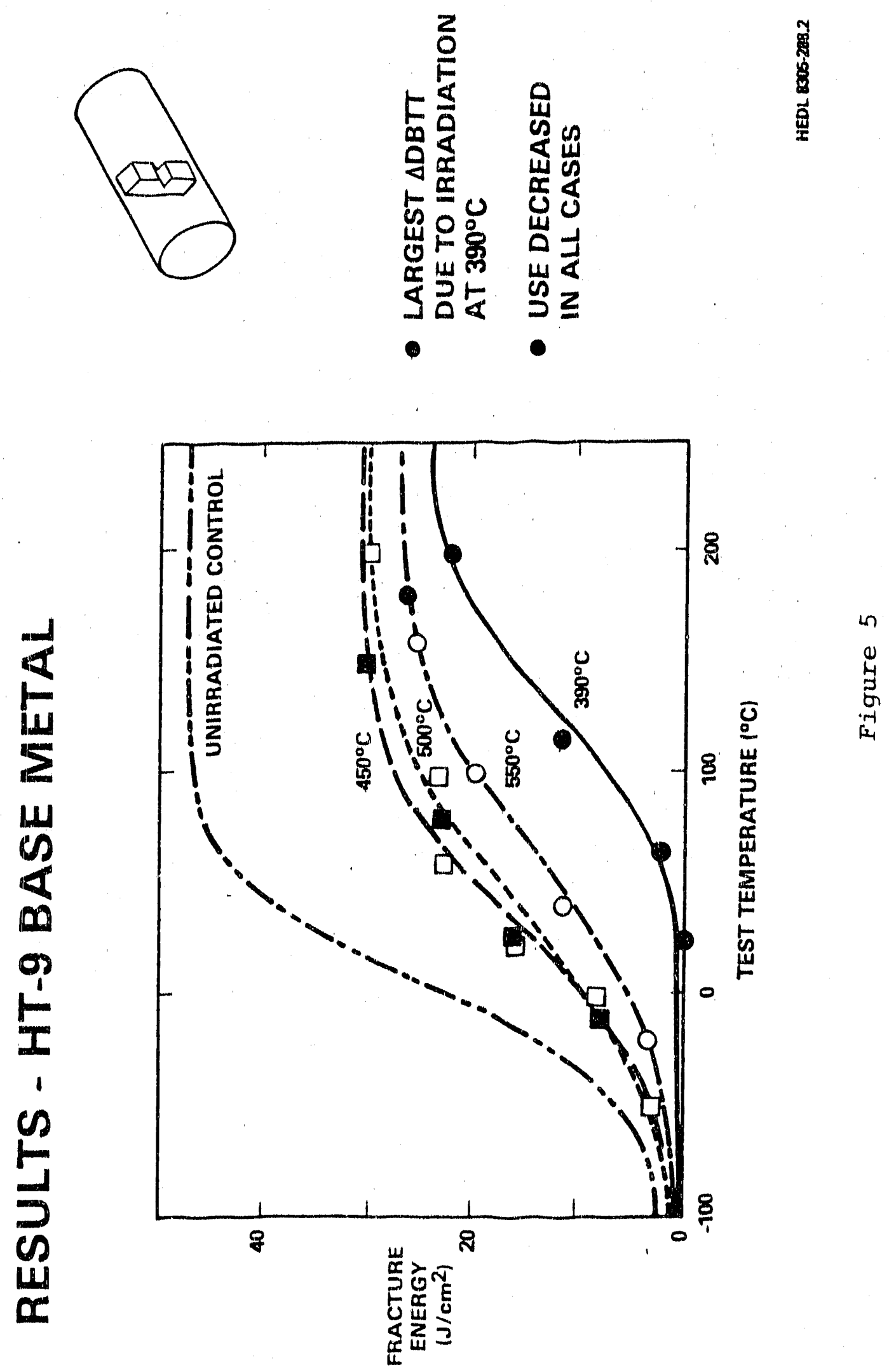


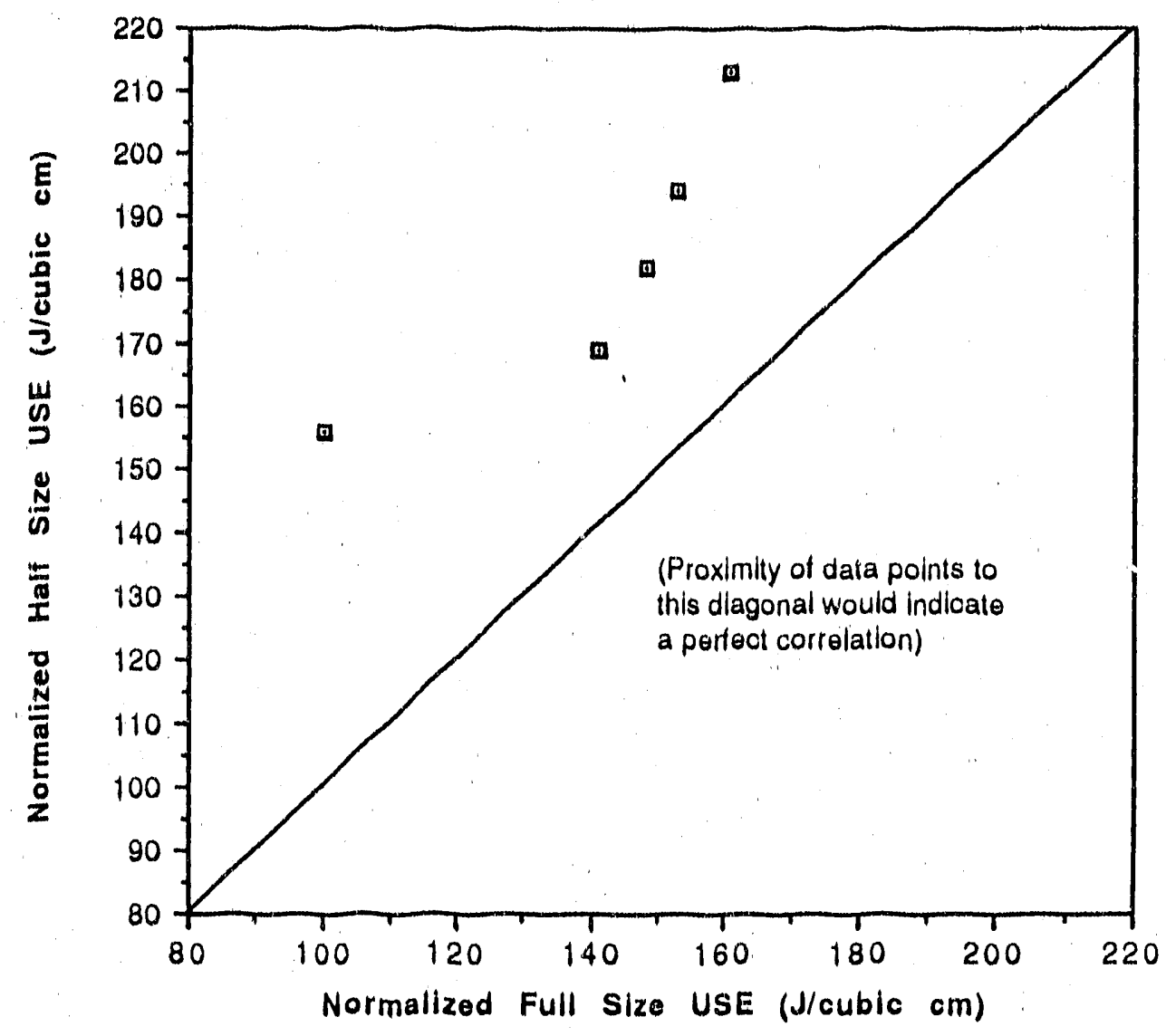

Figure 6 - Normalized for Half size and Full size specimens from Corwin \& Houghland (4) and Alexander \& Klueh (15) 


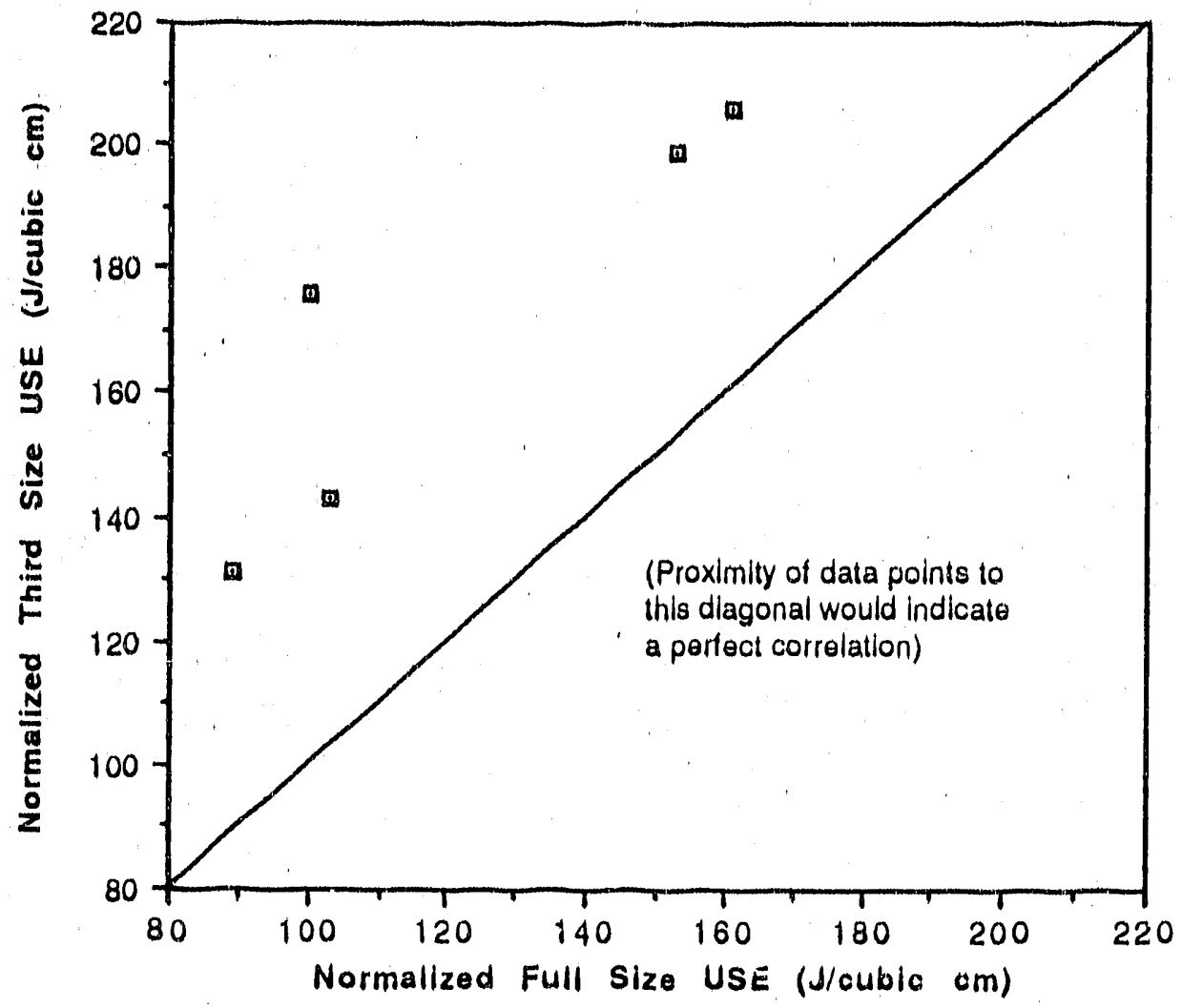

Figure 7 - Normalized USE for Third slze vs Full size specimens from Corwin \& Houghland (4) and Alexander \& Klueh (15) 
